\title{
Seasonal and Regional Variations in Metal Contamination and Condition Indicators in Yellow Perch (Perca flavescens) along Two Polymetallic Gradients. III. Energetic and Physiological Indicators
}

\author{
Patrice Couture, ${ }^{1}$ James W. Rajotte, ${ }^{2}$ and Greg G. Pyle ${ }^{3}$ \\ ${ }^{1}$ Institut National de la Recherche Scientifique, centre Eau, Terre et \\ Environnement (INRS-ETE), Université du Québec, QC, Canada; ${ }^{2}$ Department of \\ Biology, Laurentian University, Sudbury, ON, Canada; ${ }^{3}$ Department of Biology, \\ Nipissing University, North Bay, ON, Canada
}

\begin{abstract}
The influences of metal contamination, fish size, season, and region on tissue metabolic capacities and protein concentrations were examined in yellow perch from two metal gradients (Sudbury, Ontario, and Rouyn-Noranda, Québec, Canada) in two seasons (spring and summer). In general, increased tissue $\mathrm{Cu}$ and $\mathrm{Cd}$ contamination was associated with lower aerobic capacities, suggesting direct metal inhibition of aerobic enzymes. However, our data also revealed that tissue Ni contamination positively affected aerobic capacities, possibly due to oxidative damage to mitochondrial membranes leading to compensatory increases in the activity of mitochondrial enzymes. Tissue aerobic capacities decreased, but anaerobic capacities increased, with size. Tissue protein concentrations and metabolic capacities were also influenced by season. A novel finding of this study is that size-corrected tissue enzyme activities can differ markedly in yellow perch sampled in the same season in similar lakes, but separated by a few hundred kilometers. Overall, the results from this large dataset support that tissue metabolic capacities are under seasonal and regional influences, but are also affected by metal contamination. Our study indicates that tissue metabolic enzyme activities should be considered as a tool for ecological risk assessment studies aiming at detecting metal stress in wild fish. However, fish should be sampled over a short period, and reference sites should be close to contaminated sites.
\end{abstract}

Key Words: yellow perch, metals, metabolic capacities, metabolic scaling, seasonality, regional variations.

Address correspondence to Patrice Couture, Institut National de la Recherche Scientifique, Centre Eau, Terre et Environnement (INRS-ETE), Université du Québec, 490 rue de la Couronne, Québec QC Canada G1K 9A9. E-mail: patrice_couture@ete.inrs.ca 


\section{Metal Effects on Wild Yellow Perch Metabolic Status}

\section{INTRODUCTION}

Recent studies have suggested that metabolic capacities, measured using maximal activities (Vmax) of key enzymes of aerobic, anaerobic, and anabolic pathways, are affected by metal contamination in wild yellow perch (Perca flavescens) under chronic metal stress. The first study examining this question (Rajotte and Couture 2002) reported that metal-contaminated yellow perch exhibited lower aerobic capacities, as indicated by citrate synthase (CS), a mitochondrial enzyme that is part of the citric acid cycle, and $\beta$-hydroxyacyl coenzyme A dehydrogenase, an enzyme involved in mitochondrial lipid catabolism, as well as critical swimming speed, a test that measures the maximal aerobic (sustainable) swimming speed. In a subsequent study (Couture and Kumar 2003), we reported that when liver $\mathrm{Cu}$ or Cd concentration doubled, resting oxygen consumption rate decreased by $25 \%$, and aerobic scope decreased by $42 \%$, respectively, in wild yellow perch along a contamination gradient, and confirmed a lower muscle CS activity in contaminated fish, suggesting that mitochondria may be primary targets for inhibition by metals. In a further investigation (Audet and Couture 2003), in addition to reporting again lower aerobic capacities in metal-contaminated fish, we also reported that tissue protein concentrations and indicators of biosynthetic capacities were lower in yellow perch from a metal-contaminated lake compared with fish from a clean lake. Taken together, these results indicated that chronic metal exposure could lead to an impairment of aerobic and biosynthetic capacities in wild yellow perch. We therefore proposed that muscle aerobic capacities could be used in combination with other indicators to assess the effects of metal contamination on the health of yellow perch (Couture and Rajotte 2003).

Prior to our investigations of metabolic capacities in contaminated fish, we reported that the condition of yellow perch, examined using morphometric indicators, as well as tissue metal concentrations, varied seasonally (Eastwood and Couture 2002). Therefore, we also examined whether yellow perch metabolic capacities varied seasonally. A study addressing this question (Audet and Couture 2003) revealed important seasonal variations in condition and aerobic capacities, which if ignored could affect assessments of metabolic impairment in contaminated wild fish.

The studies just reviewed were all carried out in the Sudbury region of northeastern Ontario, Canada. Other researchers concurrently examined metal contamination and condition of yellow perch in Rouyn-Noranda, Québec (Laflamme et al. 2000; Sherwood et al. 2000), or in both regions (Campbell et al. 2005) and also concluded that contaminated fish exhibited lower condition than clean fish. However, the focus of these studies was somewhat different than the Sudbury investigations, and metabolic capacities were not examined except for one study (Levesque et al. 2002), which also reported metabolic impairment in contaminated fish.

In the present study, we sampled a large number of yellow perch in five lakes representing metal gradients in each of the Sudbury and Rouyn-Noranda regions, in order to complement and extend observations from the previous studies by standardizing sampling methodologies over two regions (Sudbury and Rouyn-Noranda) and two seasons (spring and summer). We reported that seasonal variations in tissue metal contamination were inconsistent between regions, and suggested that fish from Sudbury, but not Rouyn-Noranda, may have evolved mechanisms to reduce metal uptake 


\section{P. Couture et al.}

owing to the longer period of contamination of Sudbury-area lakes (Couture et al. 2008). Fish from Sudbury had lower condition than those from Rouyn-Noranda, higher condition occurred in the summer than in the spring, and fish from contaminated lakes had lower condition than those from cleaner lakes. (Pyle et al. 2008).

The first objective of this research was to investigate the influences of dietary and tissue metal concentrations on tissue metabolic capacities and protein contents in wild yellow perch. The second objective was to examine the influences of size and age (morphometric factors), season (abiotic factors) and region (genetic factors) on metabolic capacities and tissue protein concentrations. This large-scale study contributes to our understanding of metal effects and natural influences on metabolic capacities in wild fish. Ultimately, the goal of this research is to contribute toward the development of tissue metabolic capacities as a tool for ecological risk assessment (ERA) and environmental effects monitoring. Finally, results presented here orient future investigations examining the mechanisms of metabolic toxicity in wild fish under chronic exposure to metals.

\section{MATERIALS AND METHODS}

\section{Fish Sampling}

Yellow perch ( $\mathrm{n}=120$ per lake per season) of the maximum size range obtainable were captured in spring and summer in 5 lakes ( 2 clean, 1 intermediate, and 2 contaminated) in each of the 2 study gradients studied (Sudbury (S) in 2002 and Rouyn-Noranda (RN) in 2003), as previously described. (Couture et al. 2008).

\section{Enzyme Assays}

Enzyme analyses and protein assays were carried out on white muscle and liver of the same subset of fish used for analysis of tissue metal concentrations. (Couture et al. 2008). Liver and muscle CS, lactate dehydrogenase (LDH), and protein assays were carried out as previously described (Rajotte and Couture 2002). Tissue cytochrome C oxidase (CCO) activity was determined following the method of Pelletier et al. (1994). Because of an Ontario-wide power outage during summer 2003 and consequent thawing of some liver samples collected in spring 2003 in the RN region, enzyme activities could not be measured in these samples. Therefore, for these parameters no analysis of seasonal variations or regional comparisons in the spring was carried out. Specifically, seasonal variations of liver enzyme activities presented here were only carried out for $\mathrm{S}$ fish, whereas regional comparisons of these parameters could only be performed in summer. Mean values of enzyme activities and protein concentrations for each lake and season are available with the authors.

\section{Calculations and Statistics}

Preliminary data analysis revealed that tissue protein concentration and enzyme activity were related to fish size (including weight and length). Therefore, data were analyzed using a multivariate analysis of covariance (MANCOVA) to control for family-wise error rates resulting from multiple univariate analyses on a single dataset. Fish fork length, as a surrogate for fish size, was used as a covariate in the 


\section{Metal Effects on Wild Yellow Perch Metabolic Status}

MANCOVA model. The analysis included tissue enzyme activities (including total protein, $\mathrm{LDH}, \mathrm{CS}$, and CCO in liver and muscle tissues, respectively) as dependent variables and region ( $\mathrm{RN}$ or $\mathrm{S}$ ) and season (spring or summer) as independent variables. Canonical correlation analysis (as part of the MANCOVA model) allowed for the ordination of biomarkers (i.e., tissue protein concentrations and enzyme activities) together with the influence of independent variables both together and alone. Canonical scores were used to extract ordination axes for the whole model and both main effects (season and region), which were then used in subsequent Pearson correlation analyses with tissue metal concentrations (tissue metal concentrations are in Couture et al. 2008).

Analyses were conducted on $\log _{10}$-transformed data to improve parametric assumptions (Levene's test was used to test for homogeneity of variance, and ShapiroWilk's test was used to test for normality). Seasonal and regional differences in muscle and liver protein concentrations and enzyme activities were reported as least square means and adjusted for the whole multivariate model. Mean differences were considered significant when $p \leq .05$, using either an approximated or exact $F$ statistic (depending on the analysis) from a transformed Wilk's $\Lambda$. All statistical analyses were conducted using JMP version 5.1 statistical software.

\section{RESULTS}

\section{Relationships between Age and Size versus Tissue Protein Concentrations and Enzyme Activity}

Relationships using either age, weight (data not shown), or length (Tables 1 to 3) as an independent variable versus protein concentrations or enzyme activities were similar, which was expected given the strong correlations among age, length,

Table 1. Sample size, $\mathrm{R}^{2}$ (direction of relationship in parentheses) and significance level of linear regressions between wild yellow perch tissue enzyme activities or protein concentrations and fish fork length in the pooled dataset. Analyses were conducted on $\log _{10}$-transformed data.

\begin{tabular}{lccc}
\hline & $n$ & $\mathrm{R}^{2}$ & $P$ \\
\hline Liver & & & \\
$\quad$ Protein & 409 & $0.063(+)$ & $<.0001$ \\
LDH & 357 & $0.042(+)$ & $<.0001$ \\
CS & 364 & $0.142(+)$ & $<.0001$ \\
CCO & & $\mathrm{NS}$ & \\
Muscle & & $0.043(+)$ & $<.0001$ \\
Protein & 428 & $0.165(+)$ & $<.0001$ \\
LDH & 429 & $0.152(-)$ & $<.0001$ \\
CS & 429 & $0.034(-)$ & \\
CCO & 429 & &
\end{tabular}

NS, not significant $(p>.05)$. 


\section{P. Couture et al.}

Table 2. Sample size, $\mathrm{R}^{2}$ (direction of relationship in parentheses) and significance level of linear regressions between wild yellow perch tissue enzyme activities or protein concentrations and fish fork length analyzed by season. Analyses were conducted on $\log _{10}$-transformed data.

\begin{tabular}{|c|c|c|c|c|c|c|}
\hline & \multicolumn{3}{|c|}{ Spring } & \multicolumn{3}{|c|}{ Summer } \\
\hline & $n$ & $\mathrm{R}^{2}$ & $p$ & $n$ & $\mathrm{R}^{2}$ & $p$ \\
\hline \multicolumn{7}{|l|}{ Liver } \\
\hline Protein & 226 & $0.256(+)$ & $<.0001$ & & NS & \\
\hline $\mathrm{LDH}$ & 173 & $0.033(+)$ & .0167 & 184 & $0.050(+)$ & .0022 \\
\hline CS & 182 & $0.255(+)$ & $<.0001$ & 182 & $0.093(+)$ & $<.0001$ \\
\hline $\mathrm{CCO}$ & & $\mathrm{NS}$ & & 184 & $0.048(-)$ & .0028 \\
\hline \multicolumn{7}{|l|}{ Muscle } \\
\hline Protein & 244 & $0.040(+)$ & .0016 & 184 & $0.053(+)$ & .0016 \\
\hline $\mathrm{LDH}$ & 244 & $0.173(+)$ & $<.0001$ & 185 & $0.170(+)$ & $<.0001$ \\
\hline CS & 244 & $0.169(-)$ & $<.0001$ & 185 & $0.412(-)$ & $<.0001$ \\
\hline $\mathrm{CCO}$ & & NS & & 185 & $0.115(-)$ & $<.0001$ \\
\hline
\end{tabular}

NS, not significant $(p>.05)$.

and weight in the dataset. Therefore, only relationships using length, which were generally stronger than age or weight, are presented here.

Tissue protein concentrations and enzyme activities generally varied with fish length. Both liver and muscle protein concentration increased with fish length in the pooled dataset (Table 1). When data were separated by season, however, liver protein concentration did not change with fish size in summer (Table 2); similarly, when data were separated by region, liver protein concentration did not vary with

Table 3. Sample size, $R^{2}$ (direction of relationship in parentheses) and significance level of linear regressions between wild yellow perch tissue enzyme activities or protein concentrations and fish fork length analyzed by region. Analyses were conducted on $\log _{10}$-transformed data.

\begin{tabular}{|c|c|c|c|c|c|c|}
\hline & \multicolumn{3}{|c|}{ Rouyn-Noranda } & \multicolumn{3}{|c|}{ Sudbury } \\
\hline & $n$ & $\mathrm{R}^{2}$ & $p$ & $n$ & $\mathrm{R}^{2}$ & $p$ \\
\hline \multicolumn{7}{|l|}{ Liver } \\
\hline Protein & & NS & & 215 & $0.247(+)$ & $<.0001$ \\
\hline LDH & 171 & $0.065(+)$ & .0008 & & NS & \\
\hline $\mathrm{CS}$ & 178 & $0.093(+)$ & $<.0001$ & 186 & $0.180(+)$ & $<.0001$ \\
\hline $\mathrm{CCO}$ & 195 & $0.121(-)$ & $<.0001$ & & NS & \\
\hline \multicolumn{7}{|l|}{ Muscle } \\
\hline Protein & 241 & $0.016(+)$ & .0493 & 187 & $0.100(+)$ & $<.0001$ \\
\hline LDH & 241 & $0.192(+)$ & $<.0001$ & 188 & $0.391(+)$ & $<.0001$ \\
\hline CS & 241 & $0.367(-)$ & $<.0001$ & 188 & $0.060(-)$ & .0007 \\
\hline $\mathrm{CCO}$ & 241 & $0.214(-)$ & $<.0001$ & 188 & $0.023(-)$ & .0384 \\
\hline
\end{tabular}

NS, not significant $(p>.05)$. 


\section{Metal Effects on Wild Yellow Perch Metabolic Status}

fish size in Rouyn-Noranda (RN; Table 3). As for protein concentrations, tissue LDH activities systematically increased with fish length, except in liver where the relationship was not significant when Sudbury (S) fish alone were examined.

Whether data were pooled (Table 1), separated by season (Table 2), or region (Table 3), liver CS activity systematically increased with fish length, whereas in muscle it decreased. Tissue CCO activity was much more weakly correlated to fish length, but always negatively correlated when relationships were significant. In pooled data, muscle but not liver CCO activity decreased with fish length (Table 1). Liver CCO activity, however, decreased with fish length in summer but not in spring (Table 2), and in RN but not in S fish (Table 3). Muscle CCO activity consistently decreased with fish length when data were pooled (Table 1) or examined by region (Table 3), but only decreased in summer and not in spring when data were separated by season (Table 2).

\section{Whole MANCOVA Model}

Complex relationships among muscle and liver protein concentrations and enzyme activities and seasonal and regional effects are best presented in Figure 1, which depicts a canonical correlation ordination involving all variables. Points on the ordination that are in close proximity to one another are more similar with respect to all variables that make up the model than points that plot further away from each other. Muscle LDH loaded most strongly and positively on axis 1 while muscle CS had the strongest negative loading on axis 1 (Table 4). Muscle CS and liver CS loaded with the highest and lowest eigenvector magnitude on axis 2, respectively. Axis 1 was significantly correlated with kidney $\mathrm{Cu}, \mathrm{Ni}$, and Se, dietary $\mathrm{Cd}, \mathrm{Ni}, \mathrm{Se}$, and $\mathrm{Zn}$, and liver Ni, Se, and Zn (Table 5). Of these correlations, only dietary Ni demonstrated a positive association. Axis 2 was significantly correlated with kidney $\mathrm{Cu}, \mathrm{Ni}, \mathrm{Se}$, and $\mathrm{Zn}$, dietary $\mathrm{Ni}$ and $\mathrm{Zn}$, and liver $\mathrm{Cd}, \mathrm{Cu}, \mathrm{Ni}$, and $\mathrm{Zn}$, of which kidney, dietary, and liver $\mathrm{Ni}$, in addition to liver $\mathrm{Zn}$, concentrations were positively correlated with the axis whereas all others were negative (Table 5).

The canonical correlation ordination in Figure 1 shows a clear separation between regions and seasons. Regional and seasonal effects appeared to differentiate along both axes. However, a larger separation between the two regions, Sudbury and Rouyn-Noranda, was apparent along axis 1 than the seasonal separation. On axis 2, Rouyn-Noranda plotted at approximately the same magnitude as summer, while Sudbury plotted similarly to spring. On axis 1 , Sudbury plotted relatively close to summer, while Rouyn-Noranda plotted close to spring. Vectors depicted in Figure 1 indicate the size (vector length) and direction of relationship of the eight biomarkers studied relative to the main effects of region and season. Liver CS and CCO and muscle protein demonstrated a weak, negative relationship with canonical axis 2 . The direction of the muscle protein vector indicated that it was also weakly associated with axis 1 . Liver protein demonstrated a weak positive relationship with axis 2 . Muscle CCO and liver LDH showed weak positive relationships with both canonical axes. However, the strongest relationships with the first two canonical axes were with muscle LDH and muscle CS. Muscle LDH showed a strong relationship with axis 1 , cutting between the main effects of Sudbury and summer. Muscle CS was negatively 


\section{P. Couture et al.}

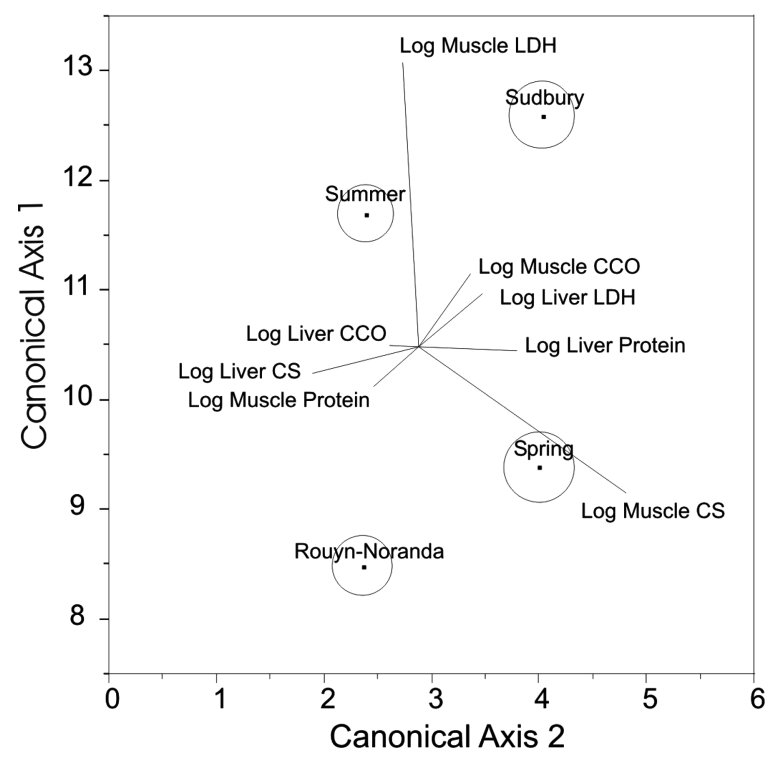

Figure 1. Canonical correlation ordination $(n=288)$ of the entire MANOVA model removing the influence of fork length as a covariate, examining the influences of region and season on protein concentration, lactate dehydrogenase ( $\mathrm{LDH}$ ) activity, citrate synthase (CS) activity, and cytochrome $\mathrm{C}$ oxidase (CCO) activity in muscle and liver tissues from wild yellow perch caught from 5 lakes in each of two metal contamination gradients in Sudbury, ON, and Rouyn-Noranda, PQ, during the spring and summer of 2002. Whole model main effects (region and season) are depicted as circles whose centers represent multivariate least squares means (centroids) and whose diameters represent $95 \%$ confidence intervals. Vector lengths and directions indicate correlation magnitude and direction, respectively, for each of the $\log _{10}$-transformed dependent variables in the analysis. Seasonal comparisons in liver include Sudbury fish only.

related to axis 1 and positively related to axis 2, plotting in a very similar direction to the main effect of spring.

\section{Effect of Region}

The effect of region on the whole multivariate model was characterized by strong positive and negative eigenvector loadings on axis 1 by muscle CS and muscle LDH, respectively, while muscle CS and muscle CCO had the strongest positive and negative loadings, respectively, on axis 2 (Table 4). Regional effects were significantly correlated with kidney $\mathrm{Cd}, \mathrm{Ni}$, and $\mathrm{Zn}$, dietary $\mathrm{Cd}$, Se, and $\mathrm{Zn}$, and liver $\mathrm{Cu}, \mathrm{Ni}, \mathrm{Se}$, and $\mathrm{Zn}$ (Table 5). Kidney $\mathrm{Cd}$ and $\mathrm{Zn}$, and liver $\mathrm{Cu}$ demonstrated a negative relationship with the regional axis, while all other significant relationships were positive.

Protein concentrations in muscle and liver tissues showed opposite trends between fish collected from Rouyn-Noranda and Sudbury. Fish from Rouyn-Noranda 


\section{Metal Effects on Wild Yellow Perch Metabolic Status}

Table 4. Eigenvectors for the first two canonical axes used to calculate canonical scores for the whole multivariate model and two main effects region and season after correcting for fish length as a covariate. The model examines the role of region and season on muscle and liver protein, lactate dehydrogenase ( $\mathrm{LDH})$, citrate synthase (CS), and cytochrome c oxidase (CCO) activities in wild yellow perch from two metal contamination gradients.

\begin{tabular}{lrrrc}
\hline Variable & \multicolumn{1}{c}{ Axis 1 } & Axis 2 & \multicolumn{1}{c}{$p$} \\
\hline Whole Model & & & 48.20 & $<.0001$ \\
Muscle Protein & -0.103 & -0.116 & $(40 / 1201.5)$ & \\
Muscle LDH & $\mathbf{0 . 3 5 6}$ & -0.021 & & \\
Muscle CS & $-\mathbf{0 . 2 9 8}$ & $\mathbf{0 . 4 3 1}$ & & \\
Muscle CCO & 0.170 & 0.121 & & \\
Liver Protein & -0.005 & 0.138 & & \\
Liver LDH & 0.074 & 0.091 & & \\
Liver CS & -0.034 & $-\mathbf{0 . 1 4 1}$ & & \\
Liver CCO & 0.001 & -0.030 & & \\
Intercept & & & & \\
Muscle Protein & $\mathbf{0 . 3 3 2}$ & 0.205 & $(8 / 275)$ & \\
Muscle LDH & -0.015 & 0.139 & & \\
Muscle CS & 0.299 & $-\mathbf{0 . 2 5 6}$ & & \\
Muscle CCO & -0.043 & 0.033 & & \\
Liver Protein & 0.122 & -0.195 & & \\
Liver LDH & 0.099 & -0.129 & & \\
Liver CS & $-\mathbf{0 . 2 4 5}$ & $\mathbf{0 . 3 1 7}$ & & \\
Liver CCO & 0.135 & 0.189 & & \\
Region & & & & \\
Muscle Protein & 0.205 & 0.007 & & \\
Muscle LDH & $-\mathbf{0 . 1 5 5}$ & -0.064 & & \\
Muscle CS & $\mathbf{0 . 3 0 5}$ & $\mathbf{0 . 4 5 6}$ & & \\
Muscle CCO & -0.072 & $-\mathbf{0 . 2 2 8}$ & & \\
Liver Protein & 0.153 & -0.118 & & \\
Liver LDH & -0.070 & 0.039 & & \\
Liver CS & -0.087 & 0.239 & & \\
Liver CCO & 0.184 & -0.030 & & \\
Season & & & & \\
Muscle Protein & -0.078 & 0.048 & & \\
Muscle LDH & 0.123 & -0.139 & & \\
Muscle CS & 0.037 & $\mathbf{0 . 3 9 3}$ & & \\
Muscle CCO & 0.097 & -0.047 & & \\
Liver Protein & -0.045 & -0.029 & & \\
Liver LDH & $-\mathbf{0 . 1 4 2}$ & 0.123 & & \\
Liver CS & $\mathbf{0 . 3 4 5}$ & 0.100 & & \\
Liver CCO & 0.131 & $-\mathbf{0 . 1 7 6}$ & & \\
\hline
\end{tabular}

Highest and lowest eigenvectors are indicated in bold. The $F$ statistic is approximated for the whole model (transformed from Wilk's $\Lambda$ ), whereas other $F$ statistics are exact. Degrees of freedom are given in parentheses below each $F$ statistic (numerator DF/denominator DF). 


\section{P. Couture et al.}

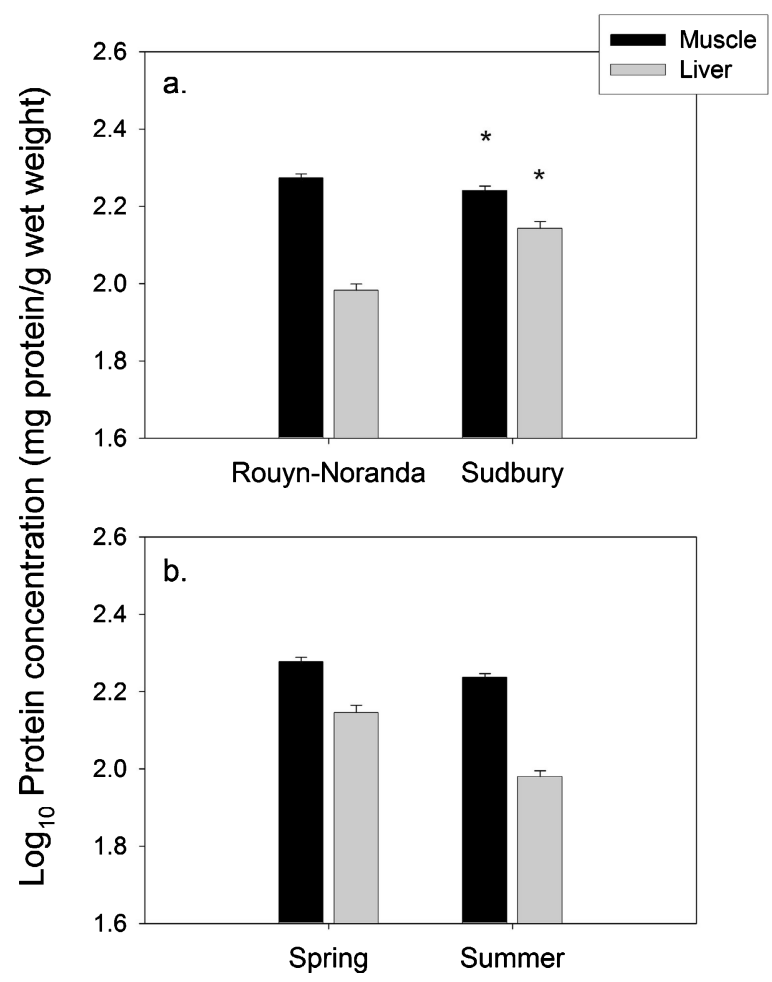

Figure 2. Effect of (a) region and (b) season on $\log _{10}$ least square mean (+ SEM) muscle and liver protein concentrations, after removing the variability associated with fork length (covariate), in wild yellow perch collected from five lakes along each of two metal-contamination gradients. Asterisks $(*)$ indicate statistically significant differences $(p<.05)$ in the same tissue. Seasonal comparisons in liver include Sudbury fish only.

had significantly higher muscle protein concentrations $\left(F_{1,282}=4.27, p=.04\right)$ and lower liver protein concentrations $\left(F_{1,282}=10.31, p=.002\right)$ than fish from Sudbury (Figure 2a). Muscle LDH activity was approximately two orders of magnitude higher than that in liver (Figure 3$)$. Neither muscle $\left(F_{1,282}=0.68, p=.41\right)$ nor liver $\left(F_{1,282}=\right.$ $3.61, p=.06) \mathrm{LDH}$ activity varied by region. Although liver CS activity did not vary by region $\left(F_{1,282}=0.01, p=.93\right)$, muscle CS activity was significantly higher in Sudbury fish than Rouyn-Noranda fish (Figure $4 \mathrm{a} ; F_{1,282}=6.26, p=.01$ ). Generally, liver CCO activity was about an order of magnitude higher than muscle CCO (Figure 5). Muscle CCO activity did not vary by region $\left(F_{1,282}=1.53, p=.22\right)$. However, liver CCO activity was significantly higher in Sudbury fish than in those from Rouyn-Noranda $\left(F_{1,282}=11.48, p=.0008\right)$.

\section{Effect of Season}

Seasonal effects on the whole multivariate model were characterized by strong positive and negative eigenvector loadings by liver CS and LDH, respectively, on axis 1 , and strong positive and negative loadings by muscle CS and liver CCO, respectively, 


\section{Metal Effects on Wild Yellow Perch Metabolic Status}

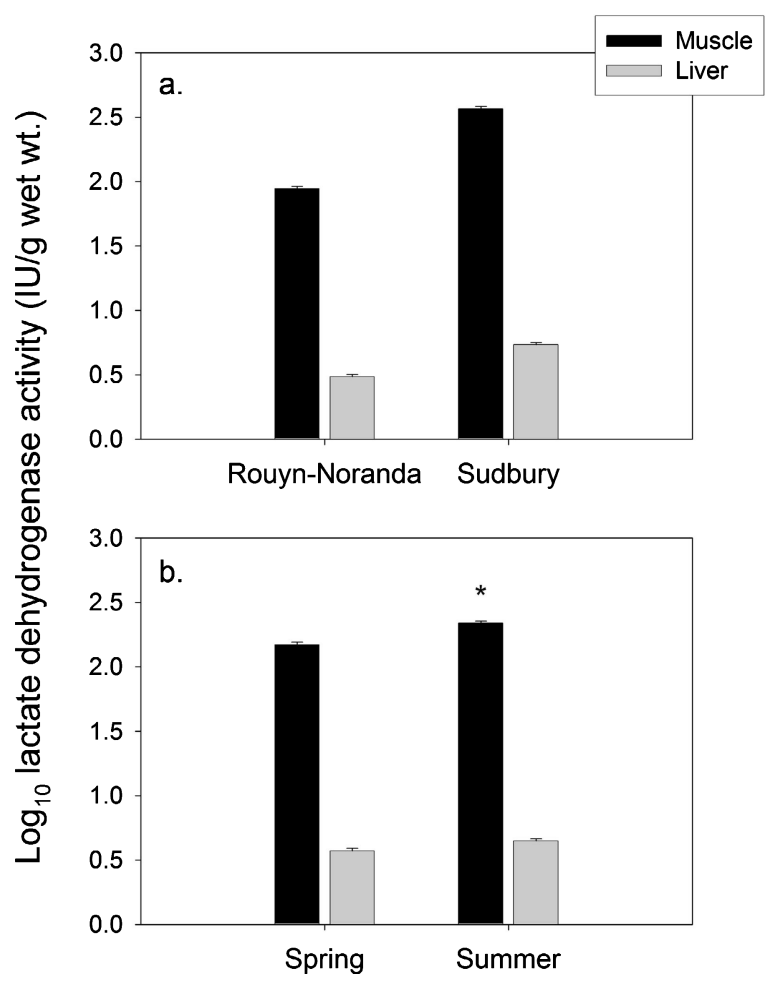

Figure 3. Effect of (a) region and (b) season on $\log _{10}$ least square mean (+ SEM; $n=58-130)$ muscle and liver lactate dehydrogenase (LDH) activity, after removing the variability associated with fork length (covariate), in wild yellow perch. Format as for Figure 2.

on axis 2, of the canonical correlation analysis (Table 4). Seasonal effects on the whole multivariate model were significantly and negatively correlated with kidney $\mathrm{Cu}, \mathrm{Se}$, and $\mathrm{Zn}$, dietary $\mathrm{Cd}$, and liver Se (Table 5).

Protein concentrations did not vary significantly by season in either muscle $\left(F_{1,282}=\right.$ $0.13, p=.72$ ) or liver tissues (Figure $2 \mathrm{~b} ; F_{1,282}=2.59, p=.11$ ). Muscle LDH activity was significantly higher in the summer than in the spring (Figure $3 \mathrm{~b} ; F_{1,282}=4.66$, $p=.03)$. However, there was no seasonal effect on liver LDH activity $\left(F_{1,282}=0.22\right.$, $p=.64)$. Citrate synthase activity demonstrated the most dramatic seasonal effect of all the biomarkers tested, such that fish collected in the summer had approximately half the muscle $\left(F_{1,282}=5.57, p=.02\right)$ and liver $\left(F_{1,282}=13.98, p=.0002\right)$ CS activity than those collected in the spring (Figure $4 \mathrm{~b}$ ). Muscle CCO activity was not affected by season (Figure $5 \mathrm{~b} ; F_{1,282}=3.47, p=.06$ ). However, liver CCO was significantly higher in the summer than in the spring $\left(F_{1,282}=6.47, p=.01\right)$.

\section{Relationships between Tissue Metals and Protein and Enzyme Biomarkers}

Pearson correlation analysis between gut content, liver and kidney metal concentrations and canonical scores generated from muscle and liver protein concentrations, and LDH, CS, and CCO activities is provided in Table 6. Both muscle and liver 


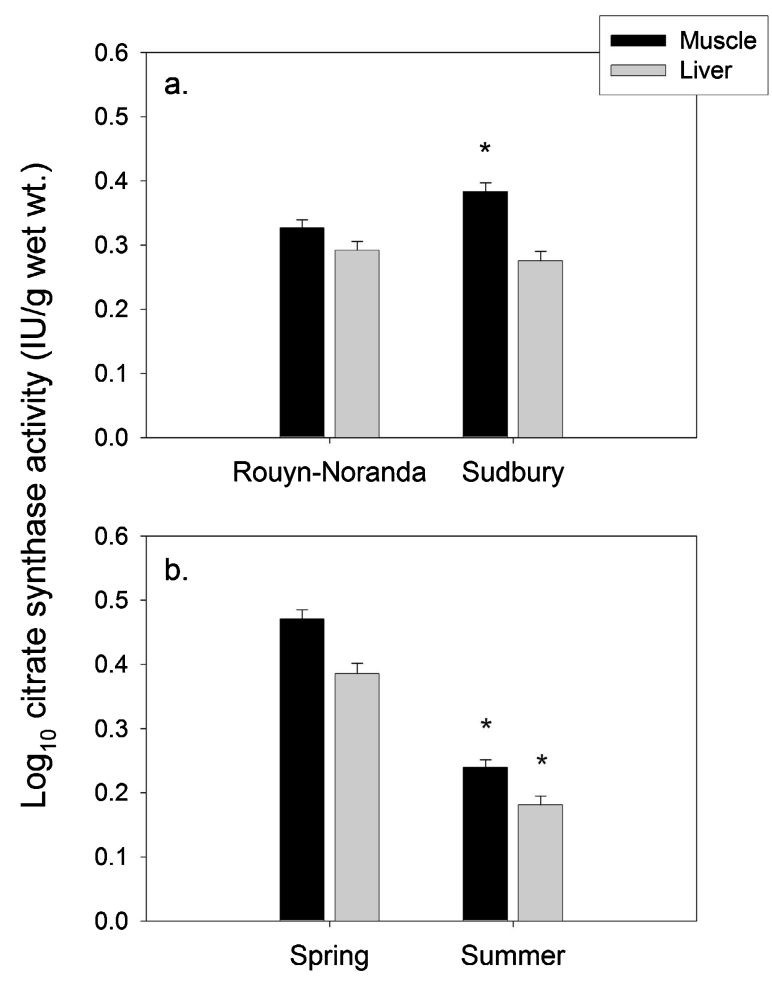

Figure 4. Effect of (a) region and (b) season on $\log _{10}$ least square mean (+ SEM; $n=58-130)$ muscle and liver citrate synthase (CS) activity, after removing the variability associated with fork length (covariate), in wild yellow perch. Format as for Figure 2.

protein concentrations were negatively associated with kidney $\mathrm{Cu}$ concentrations. Muscle protein concentration was also positively associated with dietary and liver Cd concentrations, and negatively associated with liver $\mathrm{Zn}$ concentrations. Liver protein concentrations were positively related to kidney, dietary, and liver Ni concentrations, and negatively related to liver $\mathrm{Zn}$ concentrations.

Muscle LDH activity was, in general, more strongly associated with tissue metals than liver LDH activity, as indicated by 11 significant correlations of a possible 15 for muscle compared to 3 of 15 for liver (Table 6). All significant correlations between tissue metals and muscle LDH were negative. Moreover, most of the dietary metals measured (Cd, $\mathrm{Cu}, \mathrm{Se}$, and $\mathrm{Zn}$ ) were significantly and negatively correlated with muscle LDH activity, although dietary Ni showed a positive correlation. Only kidney $\mathrm{Cd}$ and $\mathrm{Zn}$ and liver $\mathrm{Cu}$ and $\mathrm{Zn}$ yielded insignificant relationships with muscle $\mathrm{LDH}$ activity. Liver LDH activity was negatively correlated with dietary and liver Se and liver Ni concentrations.

Muscle CS activity was negatively associated with kidney and liver $\mathrm{Cu}$ and dietary Zn concentrations (Table 6). However, both kidney and liver Ni concentrations were significantly and positively associated with muscle CS activity. Liver CS activity was 


\section{Metal Effects on Wild Yellow Perch Metabolic Status}

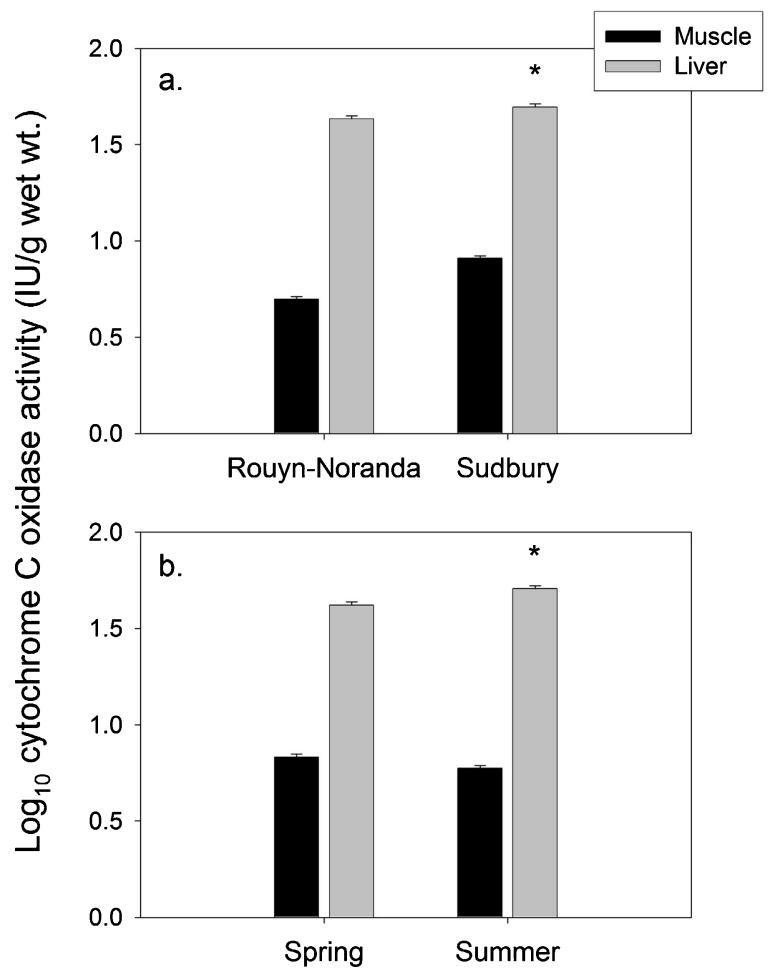

Figure 5. Effect of (a) region and (b) season on $\log _{10}$ least square mean (+ SEM; $n=58-130)$ muscle and liver cytochrome C oxidase (CCO) activity, after removing the variability associated with fork length (covariate), in wild yellow perch. Format as for Figure 2.

not negatively correlated with any metal, but was positively correlated with dietary and liver $\mathrm{Cu}$ and liver $\mathrm{Cd}$ concentrations.

Both muscle and liver CCO activities were negatively associated with kidney Se concentrations (Table 6). Although both muscle and liver CCO activities were significantly correlated with dietary Ni concentrations, muscle CCO was positively correlated and liver CCO was negatively correlated. Muscle CCO was also negatively correlated with kidney $\mathrm{Cu}$ and dietary $\mathrm{Zn}$ concentrations, and positively correlated with liver Ni concentrations. Liver CCO activities were also negatively correlated with kidney $\mathrm{Cd}, \mathrm{Ni}$, dietary $\mathrm{Cd}$, $\mathrm{Cu}$, liver $\mathrm{Cd}$ and $\mathrm{Cu}$ concentrations. Liver $\mathrm{CCO}$ activity was not positively correlated to any tissue or dietary metal measured.

\section{DISCUSSION}

Scaling of metabolic enzymes with size in fish is well known (Sullivan and Somero 1983; Goolish and Adelman 1988; Goolish 1991) and has been reported in many species including the walleye (Sander vitreus), a larger sympatric cousin of the yellow perch (Kaufman et al. 2006). The current study represents the first evidence of scaling for one anaerobic ( $\mathrm{LDH})$ and two aerobic (CS and CCO) enzymes in yellow 


\section{P. Couture et al.}

Table 5. Pearson correlation coefficients describing the relationship between yellow perch tissue metal concentrations and canonical correlation axes associated with the whole model, including the two main effects of region and season, after the variability associated with fish length was removed as a covariate $(n=209-260)$.

Whole model

\begin{tabular}{lccccc}
\hline Tissue & Metal & Axis 1 & Axis 2 & Region & Season \\
\hline Kidney & $\mathrm{Cd}$ & 0.031 & -0.105 & $-0.159^{b}$ & -0.111 \\
& $\mathrm{Cu}$ & $-0.252^{d}$ & $-0.362^{d}$ & -0.005 & $-0.444^{d}$ \\
& $\mathrm{Ni}$ & $-0.188^{b}$ & $0.146^{a}$ & $0.245^{c}$ & -0.013 \\
& $\mathrm{Se}$ & $-0.322^{d}$ & $-0.143^{a}$ & 0.118 & $-0.227^{c}$ \\
Gut contents & $\mathrm{Zn}$ & 0.071 & $-0.142^{a}$ & $-0.151^{b}$ & $-0.147^{a}$ \\
& $\mathrm{Cd}$ & $-0.272^{d}$ & 0.028 & $0.178^{b}$ & $-0.159^{b}$ \\
& $\mathrm{Cu}$ & -0.083 & -0.071 & 0.009 & -0.007 \\
& $\mathrm{Ni}$ & $0.161^{b}$ & $0.175^{b}$ & -0.066 & 0.033 \\
Liver & $\mathrm{Se}$ & $-0.229^{c}$ & -0.054 & $0.138^{a}$ & 0.024 \\
& $\mathrm{Zn}$ & $-0.296^{d}$ & $-0.128^{a}$ & $0.172^{b}$ & -0.096 \\
& $\mathrm{Cd}$ & -0.087 & $-0.138^{a}$ & -0.005 & -0.067 \\
& $\mathrm{Cu}$ & 0.098 & $-0.128^{a}$ & $-0.129^{a}$ & 0.062 \\
& $\mathrm{Ni}$ & $-0.208^{c}$ & $0.461^{d}$ & $0.413^{d}$ & 0.011 \\
& $\mathrm{Se}$ & $-0.381^{d}$ & -0.083 & $0.264^{d}$ & $-0.144^{a}$ \\
& $\mathrm{Zn}$ & $-0.174^{b}$ & $0.128^{a}$ & $0.236^{c}$ & 0.018 \\
\hline
\end{tabular}

Significance level is given in superscripts (no superscript indicates that the relationship was not significant). ${ }^{a} p \leq .05 ;{ }^{b} p \leq .01 ;{ }^{c} p \leq .001 ;{ }^{d} p \leq .0001$.

perch liver and muscle, although an allometric increase in muscle LDH activity has been reported earlier (Rennie et al. 2005). Most earlier investigations examining metabolic enzyme activities in yellow perch (Rajotte and Couture 2002; Audet and Couture 2003; Couture and Kumar 2003) selected same-sized fish to eliminate the influence of size on the data, although substantial differences in fish size among lake samples were uncorrected for in another study (Levesque et al. 2002). Here, we selected the widest range of fish size in every study lake in order to examine the extent to which fish size influenced tissue protein concentration and metabolic capacities. This is an important question because environmental contamination and other stressors influence fish growth, and as a result mean fish size is often different among lake populations. Consequently, fish of similar size among lakes often differ in age. Because effects of contaminants are related to time of exposure under both acute and chronic exposure regimes, an investigator may have an interest in either sampling same-aged, different-sized fish, or a range of sizes, as in this study. We must therefore be aware of size influences on the parameters under investigation, in order to apply relevant allometric corrections or statistical approaches.

In agreement with published literature, enzyme activity examined in this study scaled with size. The systematic allometric increase of $\mathrm{LDH}$ activity in both liver and muscle (Table 1) is likely a consequence of an increasing reliance on anaerobic metabolism in larger fish, for reasons reviewed elsewhere involving locomotory and 


\section{Metal Effects on Wild Yellow Perch Metabolic Status}

Table 6. Pearson correlation coefficients describing relationships between tissue metal concentrations and canonical scores associated with muscle and liver protein concentration and lactate dehydrogenase (LDH), citrate synthase (CS), and cytochrome c oxidase (CCO) activities in wild yellow perch from along a metal contamination gradient $(n=241-383)$.

\begin{tabular}{|c|c|c|c|c|c|c|c|c|c|}
\hline \multirow[b]{2}{*}{ Tissue } & \multirow[b]{2}{*}{ Metal } & \multicolumn{4}{|c|}{ Muscle } & \multicolumn{4}{|c|}{ Liver } \\
\hline & & Protein & LDH & CS & $\mathrm{CCO}$ & Protein & LDH & CS & $\mathrm{CCO}$ \\
\hline \multirow[t]{5}{*}{ Kidney } & $\mathrm{Cd}$ & 0.055 & -0.033 & -0.058 & 0.040 & -0.016 & 0.032 & -0.024 & $-0.272^{d}$ \\
\hline & $\mathrm{Cu}$ & $-0.132^{b}$ & $-0.271^{d}$ & $-0.350^{d}$ & $-0.266^{d}$ & $-0.158^{b}$ & -0.049 & -0.085 & -0.074 \\
\hline & $\mathrm{Ni}$ & 0.071 & $-0.190^{c}$ & $0.197^{c}$ & 0.099 & $0.136^{a}$ & -0.115 & 0.070 & $-0.145^{a}$ \\
\hline & $\mathrm{Se}$ & 0.015 & $-0.387^{d}$ & -0.091 & $-0.166^{b}$ & -0.029 & -0.064 & 0.092 & $-0.149^{a}$ \\
\hline & $\mathrm{Zn}$ & 0.057 & -0.095 & -0.071 & 0.040 & -0.104 & 0.078 & -0.054 & -0.015 \\
\hline \multirow{5}{*}{ Gut contents } & $\mathrm{Cd}$ & $0.126^{b}$ & $-0.316^{d}$ & 0.052 & 0.051 & -0.009 & -0.114 & -0.010 & $-0.271^{d}$ \\
\hline & $\mathrm{Cu}$ & 0.006 & $-0.139^{b}$ & -0.061 & -0.002 & 0.069 & -0.061 & $0.164^{b}$ & $-0.139^{a}$ \\
\hline & $\mathrm{Ni}$ & 0.077 & $0.151^{b}$ & 0.093 & $0.278^{d}$ & $0.116^{a}$ & 0.034 & -0.031 & $-0.210^{c}$ \\
\hline & $\mathrm{Se}$ & 0.083 & $-0.141^{b}$ & 0.081 & -0.056 & -0.092 & $-0.215^{c}$ & -0.022 & -0.093 \\
\hline & $\mathrm{Zn}$ & 0.032 & $-0.309^{d}$ & $-0.136^{b}$ & $-0.198^{d}$ & 0.007 & -0.041 & 0.089 & -0.036 \\
\hline \multirow{5}{*}{ Liver } & $\mathrm{Cd}$ & $0.116^{a}$ & $-0.131^{b}$ & -0.080 & -0.029 & 0.088 & -0.006 & $0.120^{a}$ & $-0.176^{c}$ \\
\hline & $\mathrm{Cu}$ & 0.044 & -0.002 & $-0.127^{a}$ & 0.098 & 0.052 & 0.082 & $0.156^{b}$ & $-0.153^{b}$ \\
\hline & $\mathrm{Ni}$ & 0.025 & $-0.119^{a}$ & $0.368^{d}$ & $0.390^{d}$ & $0.168^{b}$ & $-0.121^{a}$ & -0.067 & -0.063 \\
\hline & $\mathrm{Se}$ & 0.090 & $-0.428^{d}$ & 0.031 & -0.089 & -0.016 & $-0.187^{b}$ & 0.067 & -0.081 \\
\hline & $\mathrm{Zn}$ & $-0.162^{b}$ & -0.033 & 0.029 & 0.036 & $0.140^{b}$ & -0.094 & 0.047 & -0.042 \\
\hline
\end{tabular}

Significance level is given in superscripts (no superscript indicates that the relationship was not significant). ${ }^{a} p \leq .05 ;{ }^{b} p \leq .01 ;{ }^{c} p \leq .001 ;{ }^{d} p \leq .0001$.

other allometric constraints (Goolish 1991). Although tissue protein also generally increased with size, tissue protein and $\mathrm{LDH}$ were only weakly correlated in liver, and uncorrelated in muscle (data not shown), suggesting that tissue protein content had little influence on $\mathrm{LDH}$ activity. In contrast to $\mathrm{LDH}$, and also in agreement with the literature, aerobic enzymes (CS and CCO) generally scaled negatively with size in both liver and muscle (Tables 1-3). A noteworthy exception was for CS activity in liver, which increased systematically in larger fish from both seasons and regions. Although the decrease in aerobic capacities in larger fish can result from locomotory and other constraints that vary allometrically, the positive scaling of liver CS, but not CCO, remains unexplained. Overall, if fish tissue enzyme activities were considered as ERA tools, fish size should be statistically similar among comparison groups, or if not possible, allometric corrections should be performed.

Overall, even though allometric relationships were occasionally weaker or even absent in one season or region compared to the other, there was no contradiction of allometric trends between regions or seasons for the three enzymes examined, highlighting the general influence of size on tissue metabolic capacities. For this reason, the MANCOVA model was constructed by removing the influence of fork length (as a surrogate for size) as a covariate.

From this complex dataset, the MANCOVA analysis allowed for a clear discrimination of the effects of seasons and regions on tissue metabolic capacities. Figure 1 


\section{P. Couture et al.}

provides a summary of the complex relationships among the eight biomarkers under investigation (total protein, $\mathrm{LDH}, \mathrm{CS}$ and $\mathrm{CCO}$ in muscle and liver tissues) with respect to main effects of season and region using an optimal linear combination of variables in a canonical correlation analysis. Relative proximity among variables in this ordination indicates the degree of similarity with respect to all variables comprising the model; distant objects in the ordination suggest dissimilarity, objects close to one another reflect similarity. Vectors in the ordination indicate the degree to which a bioindicator is associated with the ordination axes as indicated by vector length, and the direction of maximum correlation.

Regions and seasons showed a clear separation on both axes of the whole multivariate model, suggesting that the metabolic condition of fish varied substantially depending on where (Sudbury or Rouyn-Noranda) or when (spring or summer) fish were sampled. Muscle CS and LDH were more affected by season than muscle CCO. Muscle LDH loaded most strongly on axis 1 in the direction of summer, in contrast to muscle CS, which loaded both strongly and positively on axis 2 and strongly and negatively on axis 1, in the direction of spring (Figure 1, Table 4). The trade-off between aerobic and anaerobic capacities, further corroborated in Figures $3 b$ and $4 b$, is well established in the literature. Aerobic and anaerobic capacities vary inversely in a variety of contexts, including temperature and body size. In the context of metal contamination, our data suggest that impairment of aerobic capacities could yield to an enhancement of anaerobic capacities. Although body size influence was removed from the MANCOVA model, seasonal variations in metabolic parameters within populations imply environmental (temperature-driven) and intrinsic (such as reproductive) factors as proximate causes. Because tissue protein concentrations did not vary seasonally (Figure $2 b$ ), changes in tissue enzyme activities reflected seasonal effects and did not merely follow the general protein pool. Our results support an earlier study that reported seasonal variations in yellow perch tissue enzyme activities (Audet and Couture 2003). If these variables were included in ERA studies, care should be taken to ensure that sampling in all study sites is conducted within a narrow period of the year in order to avoid seasonal influences on tissue metabolic capacities.

Tissue protein concentrations were higher in muscle in $\mathrm{RN}$ fish, but lower in liver, compared to $\mathrm{S}$ fish (Figure 2a). This result may be related to the lower growth, fish condition, and generally smaller size of $\mathrm{S}$ fish compared to $\mathrm{RN}$ fish (Pyle et al. 2008). Indeed, muscle protein concentrations have been associated with higher growth and condition in yellow perch and other fish species (Guderley et al. 1996; Dutil et al. 1998; Audet and Couture 2003). Higher liver protein content in S fish could indicate that these fish invest more in biological processes other than muscle growth (such as metal detoxification). Although anaerobic capacities, as measured by tissue LDH activity, did not vary significantly regionally overall (Figure 3a), S fish exhibited higher aerobic capacities in both tissues compared to RN fish, as indicated by CS in muscle and CCO in liver. This study is the first to report that tissue enzyme activities of fish from the same species (in an analysis correcting for size effects) sampled at the same period of a year in similar lakes can vary in regions separated by a few hundred kilometers. This finding implies that ERA studies examining metal effects on fish using tissue enzyme activities should include reference lakes that are in close proximity to contaminated sites. Regional differences in tissue protein contents and 


\section{Metal Effects on Wild Yellow Perch Metabolic Status}

metabolic capacities are probably at least partly determined by genetic differences between fish from the two contamination gradients. However, because $\mathrm{S}$ fish were sampled in 2002 and RN fish in 2003, it is also possible that inter-annual, and not regional, factors have contributed to the results, because year-to-year variability in metabolic capacities have been reported earlier in yellow perch (Couture and Rajotte 2003). Our data on seasonal and regional variations of CS and CCO, as well as the allometric relationships described earlier, support that tissue activities of the two enzymes behave independently, and hence provide different information, on metabolic responses to the environment.

Fish in this study were sampled from lakes that varied widely in metal contamination. Beyond the seasonal and regional influences described earlier, metals also influenced tissue metabolic capacities, which the MANCOVA model could discriminate from these other influences (Table 6). The following discussion focuses on the strongest correlations $(p<.001$ or lower) between tissue metal concentrations and metabolic capacities, which likely represent the dominant metal effects on metabolic capacities, although several weaker correlations ( $p=.01$ or higher) were reported. Muscle and liver protein concentrations were only weakly related to metal contamination. This study therefore does not support an earlier suggestion (Audet and Couture 2003), based on examination of only one contaminated and one clean lake in Sudbury, that tissue protein concentrations are lower in metal-contaminated fish. Muscle LDH activity was strongly and negatively associated with gut contents Cd, kidney $\mathrm{Cu}$ and $\mathrm{Ni}$, liver and kidney Se and gut contents $\mathrm{Zn}$ concentrations, but liver $\mathrm{LDH}$ activity was only negatively influenced by gut contents Se concentrations. Given that muscle LDH activity has been reported to reflect fish condition, and that it does not appear that one or a few metals in particular affect muscle LDH but rather all metals examined in general, the phenomenon observed here is likely a reflection of the negative effects of metal contamination on the morphometric condition of these fish (Pyle et al. 2008).

In comparison, correlations between tissue metal concentrations and CS and CCO activities were more focused on a few metals. Liver CS activity was not strongly associated with metals, but decreasing muscle CS activity was strongly associated with increasing kidney $\mathrm{Cu}$. A negative association between tissue $\mathrm{Cu}$ contamination and muscle CS activity has been reported in every other study where this was examined (Rajotte and Couture 2002; Audet and Couture 2003; Couture and Kumar 2003); therefore, this larger study provides strong evidence for Cu-related aerobic impairment involving inhibition of CS activity, although the mechanism remains to be identified. We hypothesize that enzymes of the Krebs cycle, of which CS is part, may be targets for direct metal inhibition, as reported in laboratory experiments for other enzymes and species (Gargiulo et al. 1996; Casalino et al. 2000). The activity of CCO in liver was negatively correlated with gut contents, liver and kidney Cd, and with gut contents $\mathrm{Ni}$ concentrations. In muscle, $\mathrm{CCO}$ activity was not correlated with tissue $\mathrm{Cd}$, but was negatively correlated with both kidney $\mathrm{Cu}$ and gut contents Zn concentrations. Some of the enzymes of the electron transport chain (ETC) are metalloenzymes, including CCO (Complex IV of the ETC), which contains Fe and $\mathrm{Cu}$. We do not know the effects of excess $\mathrm{Cu}$ on $\mathrm{CCO}$ activity, but our results suggest an inhibitory effect. Therefore, overall, tissue CCO activity, as for CS, was lower with increasing metal contamination. 


\section{P. Couture et al.}

Surprisingly, muscle CS activity was positively related to increasing kidney and liver Ni concentrations. Similar to muscle CS, muscle CCO activity was positively correlated with both gut contents and liver Ni (Table 6). To date, only negative relationships had been reported between aerobic capacity indicators and tissue metal concentrations in yellow perch. The inclusion of CCO activity and Ni contamination in this study thus brings a new perspective in our investigation of the mechanisms of metal toxicity on aerobic capacities in wild fish under chronic exposure. There is evidence from the mammalian literature (reviewed in Chakrabarti and Bai 1999) to suggest that exposure to Ni could lead to oxidative stress through the redox cycling of $\mathrm{Ni}^{2+}$ and $\mathrm{Ni}^{3+}$, which would directly catalyze the reduction of hydrogen peroxide, leading to free oxygen radical generation. In a study where yellow perch from both $\mathrm{RN}$ and $\mathrm{S}$ were sampled along metal contamination gradients, Giguère et al. (2005) reported that the concentrations of glutathione and the activity of glutathione reductase decreased in metal-contaminated fish, indicating lower levels of protection from oxidative stress. However, because increasing metal contamination was also associated with lower concentrations of malondialdehyde, the authors suggested that oxidative stress was likely of little concern in these fish. We hypothesize that in yellow perch, Ni-induced oxidative stress could cause damage to the inner mitochondrial membrane, increasing its leakiness to protons. As a response, the ETC would be required to increase its activity in order to maintain the transmembrane proton gradient and hence membrane potential, which are essential for aerobic ATP production. In support of this hypothesis, studies have reported that oxidative stress and metal exposure induce damage to the inner mitochondrial membrane and increase the activity of a number of mitochondrial enzymes, including CCO (Gargiulo et al. 1996; Vaglio and Landriscina 1999; Belyaeva et al. 2001).

It may be that Ni plays an important role in metal-induced metabolic dysfunction. Nickel concentrations in Sudbury lake sediments are significantly higher (15$1384 \mathrm{mg} / \mathrm{g} \mathrm{dw}$ ) than Rouyn-Noranda lake sediments (12-104 mg/g dw) (Couture et al. 2008), exposing yellow perch from Sudbury-area lakes to higher dietary and aqueous Ni concentrations than those from Rouyn-Noranda. The significant positive correlations between liver and kidney $\mathrm{Ni}$ concentrations and axis 2 (Table 5 ), axis 2's significant positive correlation with muscle CS, and muscle CS's positive relationship with liver and kidney $\mathrm{Ni}$ concentrations, suggest increased energetic demands due to elevated $\mathrm{Ni}$ exposure and subsequent accumulation. The positive correlation between dietary $\mathrm{Ni}$ and muscle LDH activity further supports the hypothesis of a metabolic cost of $\mathrm{Ni}$ exposure, which would be reflected by increased anaerobic capacities to meet the additional energetic requirements of $\mathrm{Ni}$ exposure.

Although MANCOVA provides a simplified and integrated interpretation of this complex dataset, basic statistical comparisons reveal a more complex story, although it remains fully consistent with the MANCOVA. For example, the MANCOVA indicated that muscle CCO activity did not vary seasonally overall (Figure 5), but that muscle CS decreased markedly between spring and summer (Figure 4), whereas muscle LDH increased significantly but modestly. When looking at seasonal variations for each individual lake (data not shown, available from the authors on request), muscle CS activity was lower in summer in all 10 lakes examined, but CCO was 


\section{Metal Effects on Wild Yellow Perch Metabolic Status}

also lower in 5 of the 10 comparisons, while muscle LDH activity increased in 7 of the 10 comparisons in summer. Hence, the statistical strength of the MANCOVA comparisons reflected the proportion of statistically significant individual (lake) comparisons.

Taken together, these data reveal general patterns of enzyme activity related to environmental contamination over broad spatial and temporal scales. However, fish populations from individual lakes respond independent of those from other lakes, sometimes differently than the general trends, because of a myriad complex factors (not measured in our study) inherent to natural ecosystems. General patterns of seasonal variations for muscle include a strong decrease of CS, a slight increase in $\mathrm{LDH}$, and little change in CCO between spring and summer. For liver, an incomplete dataset for RN fish in spring precludes drawing strong conclusions. However, data from S fish suggest that liver LDH activity changes little, but that CCO activity may increase slightly and that liver CS activity, as in muscle, decreases sharply between spring and summer. Tissue metabolic capacities were also overall higher in S fish. Among the natural factors known to affect tissue metabolic capacities in yellow perch, muscle aerobic and anaerobic capacities are related to swimming activity levels, which vary depending on the extent of predation pressure by walleye, itself modulated by the presence or absence of alternative prey (Kaufman et al. 2006). Because fish diversity varies naturally among lakes and is also affected by metal contamination (Sherwood et al. 2000; Pyle et al. 2005), factors other than direct metal effects also clearly affect tissue metabolic capacities in yellow perch.

Beyond seasonal, regional, and other natural influences, this study provides evidence that chronic metal exposure affects metabolic capacities, and most importantly provides clues to orient future mechanistic studies examining mechanisms of toxicity, which are essential to determine the extent of direct versus indirect effects of metals on metabolic enzymes. Specifically, the effects of $\mathrm{Cd}, \mathrm{Cu}$, and $\mathrm{Ni}$ at environmentally relevant concentrations on the generation of ROS and on mitochondrial metabolism and enzyme function warrant further investigations.

Effects of metals on tissue metabolic capacities in wild yellow perch have been reported in a number of earlier studies (Rajotte and Couture 2002; Audet and Couture 2003; Couture and Kumar 2003). This larger study strengthens the case for including measurements of tissue enzyme activities as additional tools for ERA of metal effects in wild fish. It also provides new evidence, and strengthens existing evidence, that fish size, seasons, and geographic distance affect fish tissue metabolic capacities, and must therefore be considered in the design of ERA studies.

\section{ACKNOWLEDGMENTS}

This research was supported by a grant from the Metals in the Environment Research Network to PG and GP as well as by NSERC Discovery funding to PC. Renée Stewart, Joelle Violette, Patrick Busby, and Mehran Bakhtiari provided assistance with field work in Sudbury. We thank two anonymous referees for their very useful review comments. 


\section{P. Couture et al.}

\section{REFERENCES}

Audet D and Couture P. 2003. Seasonal variations in tissue metabolic capacities of yellow perch (Perca flavescens) from clean and metal-contaminated environments. Can J Fish Aquat Sci 60:269-78

Belyaeva EA, Glazunov VV, Nikitina ER, et al. 2001. Bivalent metal ions modulate Cd ${ }^{2+}$ effects on isolated rat liver mitochondria. J Bioenerg Biomembr 33:303-18

Campbell PGC, Giguere A, Bonneris E, et al. 2005. Cadmium-handling strategies in two chronically exposed indigenous freshwater organisms-the yellow perch (Perca flavescens) and the floater mollusc (Pyganodon grandis). Aquat Toxicol 72:83-97

Casalino E, Calzaretti G, Sblano C, et al. 2000. Cadmium-dependent enzyme activity alteration is not imputable to lipid peroxidation. Arch Biochem Biophys 383:288-95

Chakrabarti SK and Bai C. 1999. Role of oxidative stress in nickel chloride-induced call injury in rat renal cortical slices. Biochem Pharmacol 58:1501-10

Couture P and Kumar PR. 2003. Impairment of metabolic capacities in copper and cadmium contaminated wild yellow perch (Perca flavescens). Aquat Toxicol 64:107-20

Couture P and Rajotte JW. 2003. Morphometric and metabolic indicators of metal stress in wild yellow perch (Perca flavescens) from Sudbury, Ontario: A review. J Environ Monit 5:216-21

Couture P, Busby P, Rajotte J, et al. 2008. Seasonal and regional variations of metal contamination and condition indicators in yellow perch (Perca flavescens) along two polymetallic gradients. I. Factors influencing tissue metal concentrations. Hum Ecol Risk Assess (this issue)

Dutil J-D, Lambert Y, Guderley H, et al. 1998. Nucleic acids and enzymes in Atlantic cod ( Gadus morhua) differing in condition and growth rate trajectories. Can J Fish Aquat Sci 55:788-95

Eastwood S and Couture P. 2002. Seasonal variations in condition and liver metal concentrations of yellow perch (Perca flavescens) from a metal-contaminated environment. Aquat Toxicol 58:43-56

Gargiulo G, Arcamone N, de Girolamo P, et al. 1996. Histochemical study of the effects of cadmium uptake on oxidative enzymes of the intermediary metabolism in kidney of goldfish (Carassius auratus). Comp Biochem Physiol C Pharmacol Toxicol 113:177-83

Giguère A, Campbell P, Hare L, et al. 2005. Metal bioaccumulation and oxidative stress in yellow perch (Perca flavescens) collected from eight lakes along a metal contamination gradient (Cd, Cu, Zn, Ni). Can J Fish Aquat Sci 62:563-77

Goolish EM. 1991. Aerobic and anaerobic scaling in fish. Biol Rev 66:33-56

Goolish EM and Adelman IR. 1988. Tissue-specific allometry of an aerobic respiratory enzyme in a large and a small species of cyprinid (Teleostei). Can J Zool 66:2199-208

Guderley H, Dutil J-D, and Pelletier D. 1996. The physiological status of Atlantic cod, Gadus morhua, in the wild and the laboratory: Estimates of growth rates under field conditions. Can J Fish Aquat Sci 53:550-7

Kaufman SD, Gunn JM, Morgan GE, et al. 2006. Muscle enzymes reveal walleye (Sander vitreus) are less active when larger prey (cisco, Coregonus artedi) are present. Can J Fish Aquat Sci 63:970-9

Laflamme J-S, Couillard Y, Campbell PGC, et al. 2000. Interrenal metallothionein and cortisol secretion in relation to $\mathrm{Cd}, \mathrm{Cu}$, and $\mathrm{Zn}$ exposure in yellow perch, Perca flavescens, from Abitibi lakes. Can J Fish Aquat Sci 57:1692-700

Levesque HM, Moon TW, Campbell PG, et al. 2002. Seasonal variation in carbohydrate and lipid metabolism of yellow perch (Perca flavescens) chronically exposed to metals in the field. Aquat Toxicol 60:257-67

Pelletier D, Dutil J-D, Blier P, et al. 1994. Relation between growth rate and metabolic organization of white muscle, liver and digestive tract of cod, Gadus morhua. J Comp Physiol 164:179-90 


\section{Metal Effects on Wild Yellow Perch Metabolic Status}

Pyle G, Busby P, Gauthier C, et al. 2008. Seasonal and regional variations of metal contamination and condition indicators in yellow perch (Perca flavescens) along two polymetallic gradients. II. Growth patterns, longevity, and condition. Hum Ecol Risk Assess (this issue)

Pyle GG, Rajotte JW, and Couture P. 2005. Effects of industrial metals on wild fish populations along a metal contamination gradient. Ecotoxicol Environ Saf 61:287-312

Rajotte JW and Couture P. 2002. Effects of environmental metal contamination on the condition, swimming performance, and tissue metabolic capacities of wild yellow perch (Perca flavescens). Can J Fish Aquat Sci 59:1296-304

Rennie MD, Collins NC, Shuter BJ, et al. 2005. A comparison of methods for estimating activity costs of wild fish populations: More active fish observed to grow slower. Can J Fish Aquat Sci 62:767-80

Sherwood GD, Rasmussen DJ, Rowan DJ, et al. 2000. Bioenergetic costs of heavy metal exposure in yellow perch (Perca flavescens): In situ estimates with a radiotracer $\left({ }^{137} \mathrm{Cs}\right)$ technique. Can J Fish Aquat Sci 57:441-50

Sullivan KM and Somero GN. 1983. Size- and diet-related variations in enzymic activity and tissue composition in the sablefish, Anoplopoma fimbria. Biol Bull 164:315-26

Vaglio A and Landriscina C. 1999. Changes in liver enzyme activity in the teleost Sparus aurata in response to cadmium intoxication. Ecotoxicol Environ Saf 43:111-16 
Copyright of Human \& Ecological Risk Assessment is the property of Taylor \& Francis Ltd and its content may not be copied or emailed to multiple sites or posted to a listserv without the copyright holder's express written permission. However, users may print, download, or email articles for individual use. 